\title{
Simple Low-Outgassing Atomic Hydrogen Source
}

\author{
Sadanori ARAE*1, Takahiko YAMAZAKI*1,*a, Kohtaro YANASE*2, Keita OCHI*2, Asuka ISHII*2, \\ Makoto OKUSAWA*2, Kazuhiko MASE*3,*4 and Masatoshi TANAKA*1 \\ ${ }^{*}$ Faculty of Engineering, Yokohama National University, 79-5, Tokiwadai, Hodogaya-ku, Yokohama 240-8501, Japan \\ ${ }^{*_{2}}$ Faculty of Education, Gunma University, 4-2 Aramaki, Maebashi 371-8510, Japan \\ *3 Institute of Materials Structure Science, KEK, 1-1 Oho, Tsukuba 305-0801, Japan \\ ${ }^{*}$ The Graduate University for Advanced Studies, 1-1 Oho, Tsukuba 305-0801, Japan
}

(Received January 31, 2012, Accepted March 21, 2012)

We constructed a simple atomic hydrogen source mounted on a conflat flange with an outer diameter of $70 \mathrm{~mm}$ (CF70). The source consists of a tungsten filament, a hydrogen gas inlet, and two feedthroughs. The filament is surrounded by a CF70 nipple made of $0.2 \%$ beryllium copper alloy and oxygen-free cupper gaskets to reduce the outgassing rate. Using this hydrogen source, we hydrogenated a clean $\mathrm{Si}(111)-7 \times 7$ surface at room temperature. Low energy electron diffraction patterns and Auger electron spectra were measured before and after the hydrogenation.

\section{Introduction}

An atomic hydrogen source is often used for surface hydrogenation under ultrahigh vacuum conditions ${ }^{1)}$. Atomic hydrogen is usually generated by the decomposition of hydrogen molecules on a hot tungsten filament at a temperature of 1500 to $1800^{\circ} \mathrm{C}^{2}$. The hot filament, however, often causes serious outgassing from the surrounding components. In the present paper we report on a simple low-outgassing atomic hydrogen source. Using this hydrogen source, we hydrogenated a clean $\mathrm{Si}(111)-7$ $\times 7$ surface at room temperature (RT).

\section{Atomic hydrogen source}

Figure 1 shows a schematic drawing and photograph of the atomic hydrogen source. It consists of a filament made of tungsten wire with a diameter of $0.6 \mathrm{~mm}$, a hydrogen gas inlet, two connectors made of molybdenum, and two electric feedthroughs. The filament is surrounded by a CF70 nipple made of forged $0.2 \%$ beryllium copper alloy $(0.2 \%-\mathrm{Be}-\mathrm{Cu}$ alloy, Vaclab Inc.), a front oxygen-free cupper (OFC) gasket with an inner diameter of $6 \mathrm{~mm}$, and a back OFC gasket with three holes. The outgassing rate of the $0.2 \%-\mathrm{Be}-\mathrm{Cu}$ alloy is reported to be $5.6 \times 10^{-13} \mathrm{~Pa} \mathrm{~m} \mathrm{~s}^{-1}\left(\mathrm{H}_{2}\right)$ at $\mathrm{RT}^{3-5)}$. This value is three orders of magnitude smaller than that of SS304 (typically $\sim 10^{-9} \mathrm{~Pa} \mathrm{~m} \mathrm{~s}^{-1}$ ). Furthermore, the thermal conductivities of the $0.2 \%-\mathrm{Be}-\mathrm{Cu}$ alloy and OFC ( 210 and $391 \mathrm{~W} \mathrm{~m}^{-1} \mathrm{~K}^{-1}$, respectively) are one order of magnitude larger than that of SS304 (typically 16.7 $\left.\mathrm{W} \mathrm{m}^{-1} \mathrm{~K}^{-1}\right)$. Therefore, increase of the pressure due to the hot tungsten filament can be suppressed when the 0.2 $\%-\mathrm{Be}-\mathrm{Cu}$ alloy nipple is cooled with air or water.

Figure 2 shows the current-temperature relationship of the atomic hydrogen source. The atomic hydrogen source was used to hydrogenate a clean $\mathrm{Si}(111)-7 \times 7$ sur-

\footnotetext{
*a Present address: Fuji Xerox Co. Ltd., Takematsu Center, 1600
} Takematsu, Minamiashigara 250-0111, Japan.

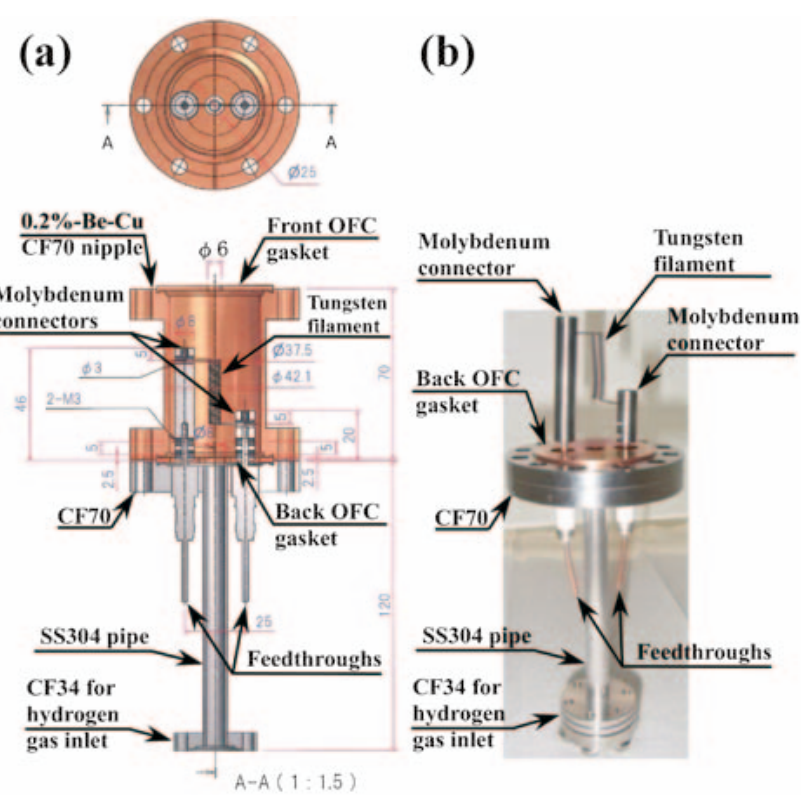

Fig. 1 (Color online) (a) Schematic drawing of the atomic hydrogen source. (b) Photograph of the atomic hydrogen source without the $0.2 \%$ beryllium copper alloy CF70 nipple.

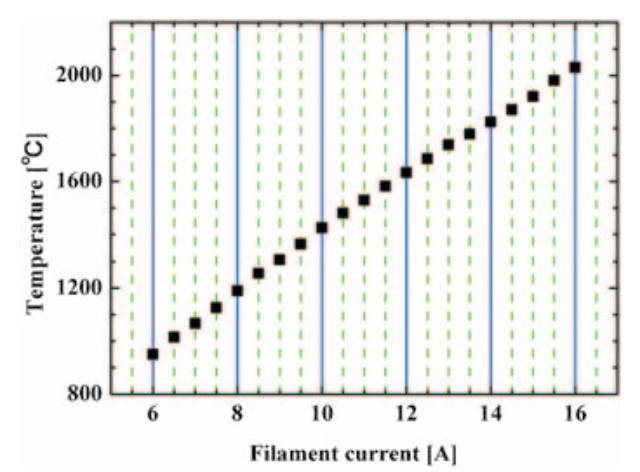

Fig. 2 (Color online) Current-temperature relationship of the atomic hydrogen source. The temperature was measured with an infrared thermometer (Japan Sensor Corporation, FTK9-R160A-10R21). The emissivity of tungsten was assumed to be 0.16 . 


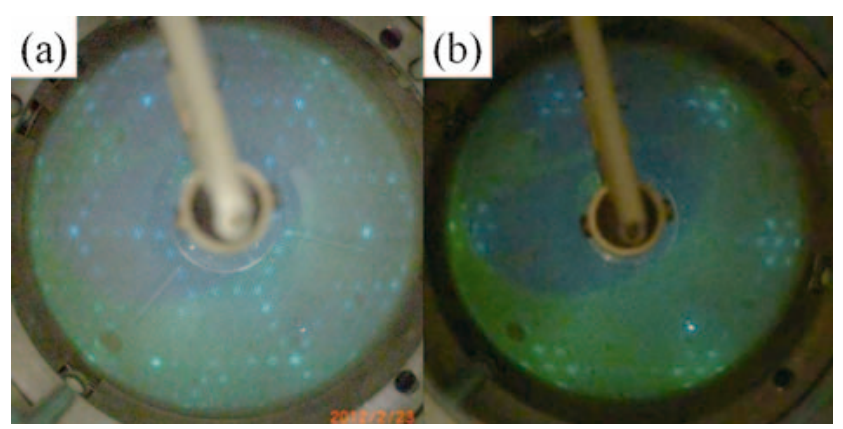

Fig. 3 (Color online) LEED patterns of $\mathrm{Si}(111)-7 \times 7$ (a) before and (b) after the hydrogenation at room temperature. The primary electron energies were (a) 85.0 and (b) $95.1 \mathrm{eV}$.

face at RT in an ultrahigh vacuum chamber with a base pressure of about $3 \times 10^{-8} \mathrm{~Pa}$. The chamber is pumped with a turbomolecular pump (Edwards, STP-301, 300 $\mathrm{L} / \mathrm{s}$ ) and two non-evaporable getter assemblies (SAES getters, GP 50, $50 \mathrm{~L} / \mathrm{s})$. The filament current was kept at 14.5 A (about $1870^{\circ} \mathrm{C}$, see Fig. 2), and the hydrogen dose amount was $1000 \mathrm{~L}\left(1 \mathrm{~L}=1.3 \times 10^{-4} \mathrm{~Pa} \mathrm{~s}\right)$. Under these conditions, $\mathrm{Si}(111)-7 \times 7$ is reported to be fully saturated with hydrogen with a coverage of 1.25-1.5 monolayers ${ }^{6,7}$ ) (MLs, $1 \mathrm{ML}=7.8 \times 10^{14} \mathrm{~cm}^{-2}$ for $\left.\mathrm{Si}(111)^{1)}\right)$. The pressure after hydrogenation was about 7 $\times 10^{-8} \mathrm{~Pa}$.

Figure 3 shows LEED patterns of $\operatorname{Si}(111)-7 \times 7$ before and after the hydrogenation at RT. The $7 \times 7$ diffraction pattern changes to the one with the $1 / 7$ reflections neighboring the fundamental reflections. The results are consistent with previous LEED studies ${ }^{6-9)}$. This structure is referred conventionally in literature as " $\delta(7 \times 7)$ ", or " $7 \times 1$ '"1). The results verify that the atomic hydrogen source works well.

Using a coaxially symmetric electron energy analyzer (ASMA) and a double-pass cylindrical mirror analyzer (DPCMA $)^{10)}$, we measured the photoelectron spectra of clean $\operatorname{Si}(111)-7 \times 7$ and $\operatorname{Si}(111)-7 \times 7$ saturated with hydrogen at RT as shown in Fig. 4. The measurements were carried out at the BL-11D in the Photon Factory (Japan). The $\mathrm{Si}-L_{23} V V$ Auger electron spectrum (AES) of $\mathrm{Si}(111)-7 \times 7$ shows a sharp peak at an electron kinetic energy $\left(E_{\text {kin }}\right)$ of about $88.5 \mathrm{eV}$ and a smooth slope down to $E_{\text {kin }}$ of $30 \mathrm{eV}$. The $\mathrm{Si}-L_{23} V V$ AES of hydrogenated $\operatorname{Si}(111)-7 \times 7$, on the other hand, show a maximum peak, a small shoulder, and a broad peak at $E_{\text {kin }}$ of about 87 , about 80 , and about $72 \mathrm{eV}$, respectively. The three-peak structure in the $\mathrm{Si}-L_{23} V V$ AES of the hydrogenated $\mathrm{Si}(111)-7 \times 7$ surface indicates that the valence electronic states are changed after the hydrogenation ${ }^{11)}$. Further discussion on the change of the valence electronic states induced by the hydrogenation will be presented elsewhere.

Since the present atomic hydrogen source is simple, economic, and low-outgassing, it is useful for the hydrogenation of surfaces under ultrahigh vacuum conditions.
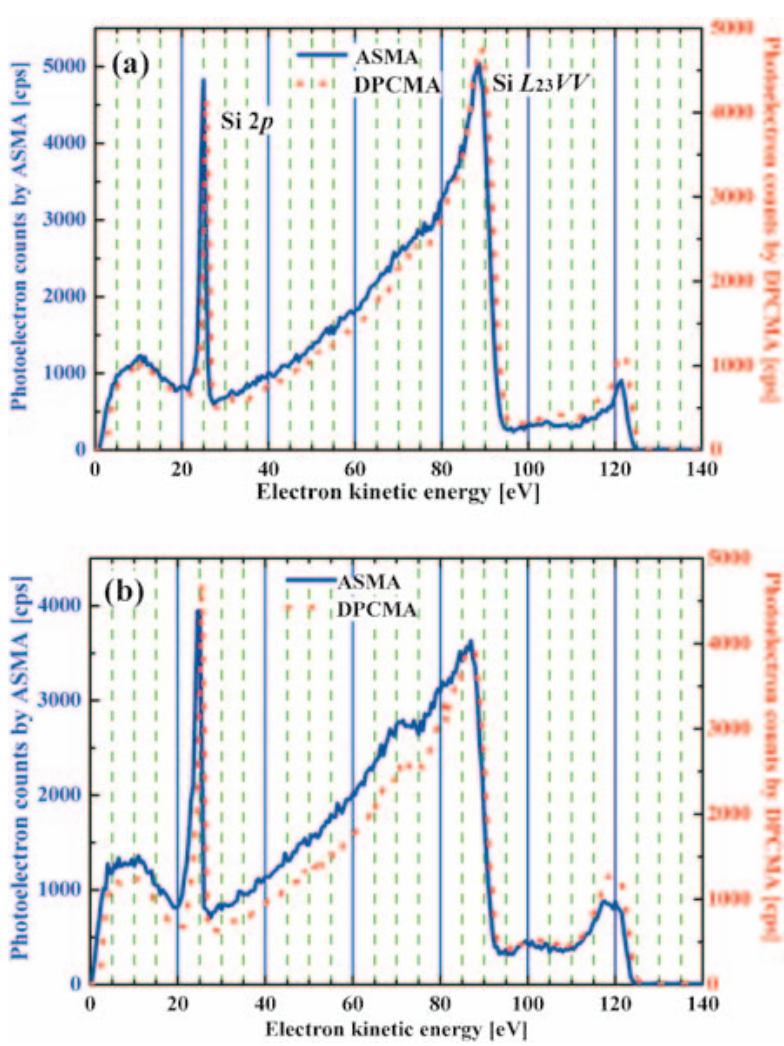

Fig. 4 (Color online) Photoelectron spectra of (a) clean $\operatorname{Si}(111)-7 \times 7$ and (b) $\operatorname{Si}(111)-7 \times 7$ saturated with hydrogen at room temperature. The spectra were measured at the BL-11D in the Photon Factory using a coaxially symmetric electron energy analyzer (ASMA) and a double-pass cylindrical mirror analyzer (DPCMA) ${ }^{10)}$. The photon energy was $130 \mathrm{eV}$.

\section{Acknowledgments}

We express our sincere thanks to Mr. Keisuke Kurita, Mr. Nariaki Shohata (University of Tsukuba), and the members of the Photon Factory for their valuable support during the course of the experiments. This work has been performed under the approval of the Photon Factory Program Advisory Committee (PF PAC No. 2011G013).

\section{References}

1) K. Oura, V. G. Lifshits, A. A. Saranin, A. V. Zotov and M. Katayama: Surf. Sci. Rep., 35 (1999) 1.

2) J. T. Yates, Jr.: Experimental Innovations in Surface Science - $A$ Guide to Practical Laboratory Methods and Instruments, (Springer-Verlag, New York, 1998) p. 682.

3) F. Watanabe: J. Vac. Sci. Technol. A, 22 (2004) 181

4) F. Watanabe: J. Vac. Sci. Technol. A, 22 (2004) 739.

5) F. Watanabe: Shinku, 49 (2006) 349.

6) K. Oura, M. Naitoh, F. Shoji, J. Yamane, K. Umezawa and T. Hanawa: Nucl. Instrum. Meth. Phys. Res. B, 45 (1990) 199.

7) R. J. Culbertson, L. C. Feldman, P. J. Silverman and R. Haight: J. Vac. Sci. Technol., 20 (1982) 868.

8) T. Sakurai and H. D. Hagstrum: Phys. Rev. B, 12 (1975) 5349.

9) E. G. McRae and C. W. Caldwell: Phys. Rev. Lett., 46 (1981) 1632 .

10) T. Kakiuchi, S. Hashimoto, N. Fujita, K. Mase, M. Tanaka and M. Okusawa: J. Vac. Soc. Jpn., 51 (2008) 749.

11) T. Yamazaki, S. Hashimoto, T. Kakiuchi, K. Mase and M. Tanaka: J. Phys.: Conf. Ser., 288 (2011) 012016. 